\title{
Der »nemo tenetur«-Grundsatz als Grenze steuerlicher Informationshilfe in der Europäischen Union
}

Zugleich ein Beitrag zu Geltung und Umfang von »nemo tenetur« innerhalb der Europäischen Union

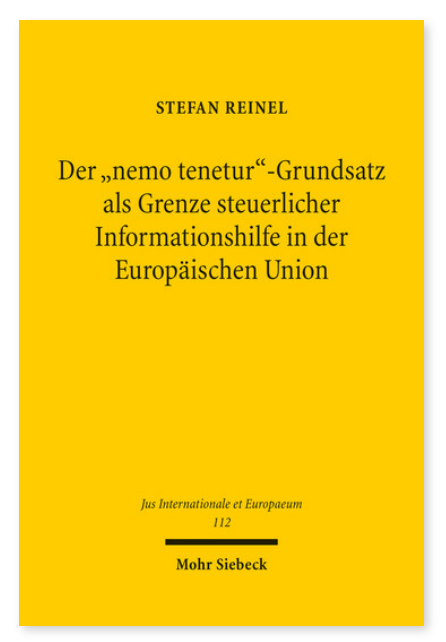

2015. XXXVIII, 512 Seiten.

JusIntEu 112

ISBN 978-3-16-152300-7

DOI 10.1628/978-3-16-152300-7

eBook PDF 109,00€

ISBN 978-3-16-152042-6

fadengeheftete Broschur 109,00€
Das zwischenstaatliche Amts- und Rechtshilferecht in Steuersachen hat in den letzten Jahrzehnten nicht nur enorm an Bedeutung gewonnen, sondern unterlag insbesondere unter dem Einfluss der Europäischen Union einem wesentlichen Wandel. Während die grenzüberschreitende Zusammenarbeit ursprünglich eher von politischen Maßstäben geprägt war, tritt zunehmend der Charakter einer Verrechtlichung hervor, der als Konsequenz vormals noch vernachlässigte Fragen des Grundrechtsschutzes deutlicher in den Vordergrund der Betrachtung rückt. In diesem Kontext verdient unter anderem der »nemo tenetur «-Grundsatz besondere Beachtung. Der steuerliche Auskunftsverkehr ist meist auf Informationen ausgerichtet, die zwangsweise von dem Steuerpflichtigen erlangt werden. Diese Informationen können auch in einem gegen ihn gerichteten Strafverfahren von Bedeutung sein. Hierbei stellt sich insbesondere die Frage, inwiefern ein europäisch verstandener »nemo tenetur «-Grundsatz den steuerlichen Informationshilfeverkehr begrenzend beeinflusst.

Stefan Reinel Keine aktuellen Daten verfügbar.

Jetzt bestellen:

https://mohrsiebeck.com/buch/der-nemo-tenetur-grundsatz-als-grenze-steuerlicher-informationshilfe-in-der-europaeischenunion-9783161523007?no_cache=1

order@mohrsiebeck.com

Telefon: +49 (0)7071-923-17

Telefax: +49 (0)7071-51104 